\title{
Mass-induced sea level change in the northwestern North Pacific and its contribution to total sea level change
}

\author{
Xuhua Cheng, ${ }^{1}$ Lijuan $\mathrm{Li},{ }^{1}$ Yan Du, ${ }^{1}$ Jing Wang, ${ }^{2}$ and Rui-Xin Huang ${ }^{3}$
}

Received 14 June 2013; revised 9 July 2013; accepted 12 July 2013; published 2 August 2013.

[1] Over the period 2003-2011, the Gravity Recovery and Climate Experiment (GRACE) satellite pair revealed a remarkable variability in mass-induced sea surface height (MSSH) in the northwestern North Pacific. A significant correlation is found between MSSH and observed total sea surface height (SSH), indicative of the importance of barotropic variability in this region. For the period 2003-2011, MSSH rose at a rate of $6.1 \pm 0.7 \mathrm{~mm} / \mathrm{yr}$, which has a significant contribution to the $\mathrm{SSH}$ rise $(8.3 \pm 0.7 \mathrm{~mm} / \mathrm{yr})$. Analysis of the barotropic vorticity equation based on National Centers for Environmental Prediction/National Center for Atmospheric Research reanalysis product, GRACE, and altimetry data suggests that the MSSH signal is primarily caused by negative wind stress curl associated with an anomalous anticyclonic atmospheric circulation. Regression analysis indicates that trends in MSSH and surface wind are related to the Pacific Decadal Oscillation, whose index had a decreasing trend in the last decade. Citation: Cheng, X., L. Li, Y. Du, J. Wang, and R.-X. Huang (2013), Mass-induced sea level change in the northwestern North Pacific and its contribution to total sea level change, Geophys. Res. Lett., 40, 3975-3980, doi:10.1002/grl.50748.

\section{Introduction}

[2] Global mean sea level rise is an indicator of global warming and a threat to the low-lying coastal regions and islands. Sea level increased at a rate of about $1.5-2.0 \mathrm{~mm} / \mathrm{yr}$ in the last century and is rising at an even higher rate $(3.4 \pm 0.4 \mathrm{~mm} / \mathrm{yr})$ in the last two decades, as observed by satellite altimetry [e.g., Douglas et al., 2001; Church and White, 2006; Cazenave and Llovel, 2010]. There are two major components of sea level variability. One is the steric component. The other is related to water mass change as a result of either ocean mass redistribution or water mass flux [Cazenave and Nerem, 2004; Chambers, 2006a]. Gill and Niiler [1973] and Willebrand et al. [1980] suggested that steric change is the major component of large-scale sea level

\footnotetext{
${ }^{1}$ State Key Laboratory of Tropical Oceanography, South China Sea Institute of Oceanology, Chinese Academy of Sciences, Guangzhou, China.

${ }^{2}$ School of Geography and Planning, Sun Yat-sen University, Guangzhou, China.

${ }^{3}$ Woods Hole Oceanographic Institution, Woods Hole, Massachusetts, USA.

Corresponding author: X. Cheng, State Key Laboratory of Tropical Oceanography, South China Sea Institute of Oceanology, Chinese Academy of Sciences, 164 West Xingang Rd., Guangzhou 510301, China. (xuhuacheng@scsio.ac.cn)

(C)2013. American Geophysical Union. All Rights Reserved. 0094-8276/13/10.1002/grl.50748
}

variability at low latitudes on a seasonal time scale, where the baroclinic response to wind dominates the barotropic response. However, the reverse is true at high latitudes.

[3] Satellite altimetry measures the combined effect of the steric and mass variations. Hydrographic observations provide a direct assessment of contribution due to steric sea level [Levitus et al., 2005]. The launch of the Gravity Recovery and Climate Experiment (GRACE) in March 2002 provides an entirely new tool for monitoring water mass change in the ocean [Tapley et al., 2004; Chambers, 2006b]. Based on analyzing these observations, global and regional sea level budgets have been discussed by different authors [e.g., Chambers and Willis, 2008; Willis et al., 2008; Cazenave et al., 2009; Llovel et al., 2011; Leuliette and Willis, 2011; Boening et al., 2012]. Willis et al. [2008] found that the observed seasonal and interannual fluctuations in sea level between mid-2003 and mid-2007 can be explained by the ocean mass and steric sea level changes. Leuliette and Willis [2011] found that the sum of the global mean steric sea level and the ocean mass component had a trend of $1.6 \pm 0.6 \mathrm{~mm} / \mathrm{yr}$ over 2004-2010, in agreement with the total sea level rise rate of $1.5 \pm 0.9 \mathrm{~mm} / \mathrm{yr}$. Chen et al. [2013] suggested that steric sea level and mass-induced sea surface height (MSSH) rose by about $0.60 \pm 0.27$ and $1.80 \pm 0.47 \mathrm{~mm} / \mathrm{yr}$ between 2005 and 2011 , respectively. The sum of the steric and mass components is in agreement with total sea level rise $(2.39 \pm 0.48 \mathrm{~mm} / \mathrm{yr})$. Boening et al. [2012] found that global sea level dropped by $5 \mathrm{~mm}$ between the beginning of 2010 and mid-2011 due to the decline in ocean mass.

[4] At the global scale, ocean mass increase results from the contribution of ice sheets, mountain glaciers melting, and continental waters. At the regional scale, ocean mass displacements, due to the atmospheric forcing (wind and sea level pressure) and variability in the oceanic circulation, may dominate the mass-induced sea level change [Cazenave and Llovel, 2010; Quinn and Ponte, 2012]. From observations, several works have verified that mass-induced sea surface height (MSSH) dominates the sea surface height (SSH) change at midlatitudes to high latitudes on intraseasonal time scales [e.g., Boening et al., 2011; Quinn and Ponte, 2012]. Quinn and Ponte [2012] found that the observed intraseasonal MSSH and total SSH are significantly coherent at high latitudes in the North Pacific and the Southern Ocean. Boening et al. [2011] revealed a record-high MSSH in late 2009 to early 2010 in the South Pacific, which explains 94\% variance in the SSH signals. Model-based studies indicated that tight relations between SSH and MSSH are found in shelf regions and higher latitudes on an interannual time scale [Bingham and Hughes, 2008].

[5] Chambers and Willis [2008] reported a significant lowfrequency fluctuation of ocean mass in the North Pacific during January 2003 to December 2007, which was in good agreement with steric-corrected SSH. Song and Zlotnicki 

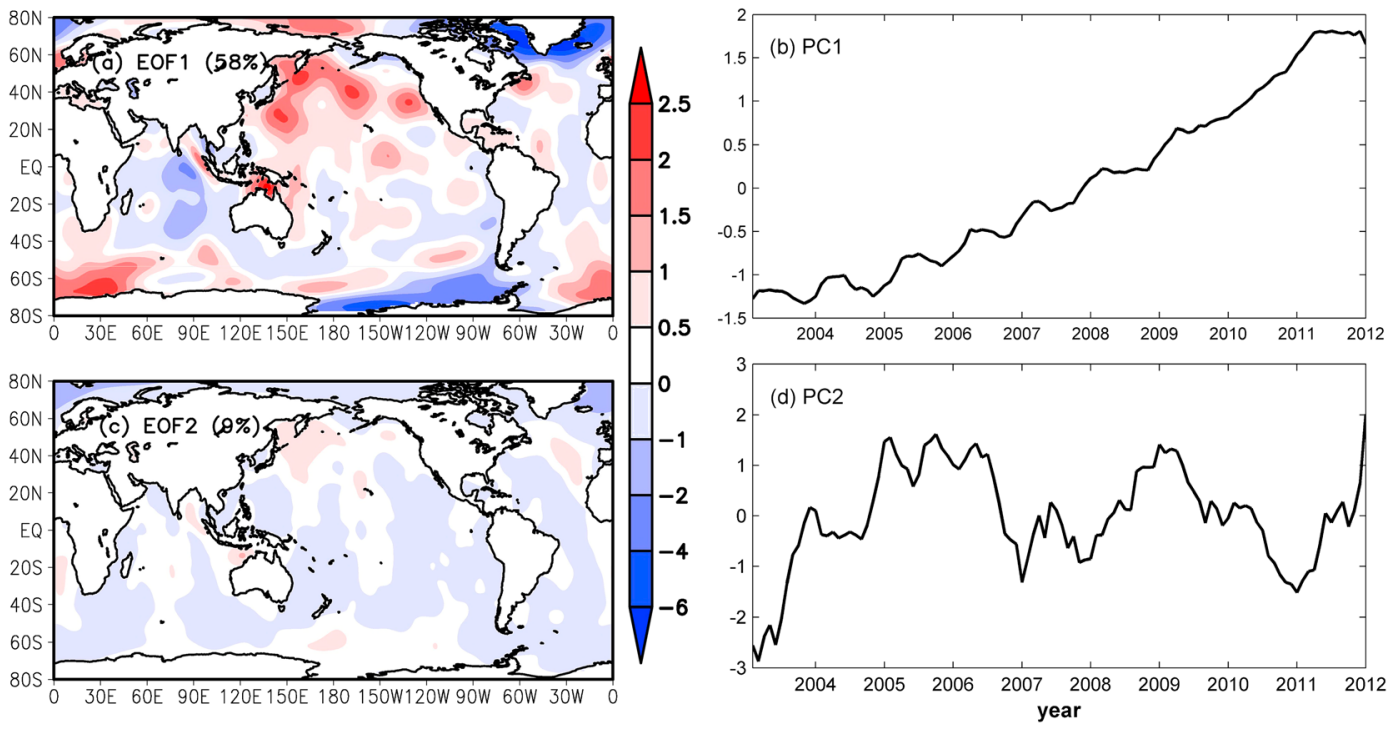

Figure 1. First two EOF patterns of the observed ocean mass (with annual cycle removed) over the (a, c) global ocean and $(b, d)$ their corresponding normalized principal components.

[2008] found a barely significant correlation between both MSSH and wind stress curl (WSC) and El Niño-Southern Oscillation (ENSO) in the region. Using longer-time span GRACE data, Chambers [2011] further confirmed the result obtained by Song and Zlotnicki [2008], and he also pointed out that ENSO-correlated variations in the MSSH do not explain the trend during 2003-2010. In this study, we reveal a remarkable variability in ocean mass in the northwestern North Pacific during 2003-2011. MSSH rose at a rate of $6.1 \pm 0.7 \mathrm{~mm} / \mathrm{yr}$ (hereafter, the uncertainty refers to formal error with $95 \%$ confidence); this is a significant contribution to the SSH trend $(8.3 \pm 0.7 \mathrm{~mm} / \mathrm{yr})$ during this period. Analysis of the barotropic vorticity equation suggested that the MSSH is primarily caused by a negative trend in WSC. The longterm trends in MSSH and surface wind may contain decadal variability related to Pacific Decadal Oscillation (PDO).

\section{Data and Method}

[6] Gridded ocean bottom pressure fields $\left(1^{\circ} \times 1^{\circ}\right)$, derived from monthly GRACE Center for Space Research Release 04 (RL04) solutions, are available from http://grace.jpl.nasa.gov/ data/mass/ [Chambers, 2006a]. Release 04 (RL04) represents a significant improvement over the previous releases of the data. A correction for postglacial rebound has been applied to the GRACE data, in order to remove the secular trend in the gravity field that is not caused by the recent water redistribution over the Earth's surface [Chambers and Bonin, 2012]. The data are smoothed spatially with a $500 \mathrm{~km}$ Gaussian smoothing. The time average over the period from January 2003 to December 2011 has been removed from the data before further analysis.

[7] The sea level anomaly (SLA) data used in this study are based on a merged product from multiple satellite missions

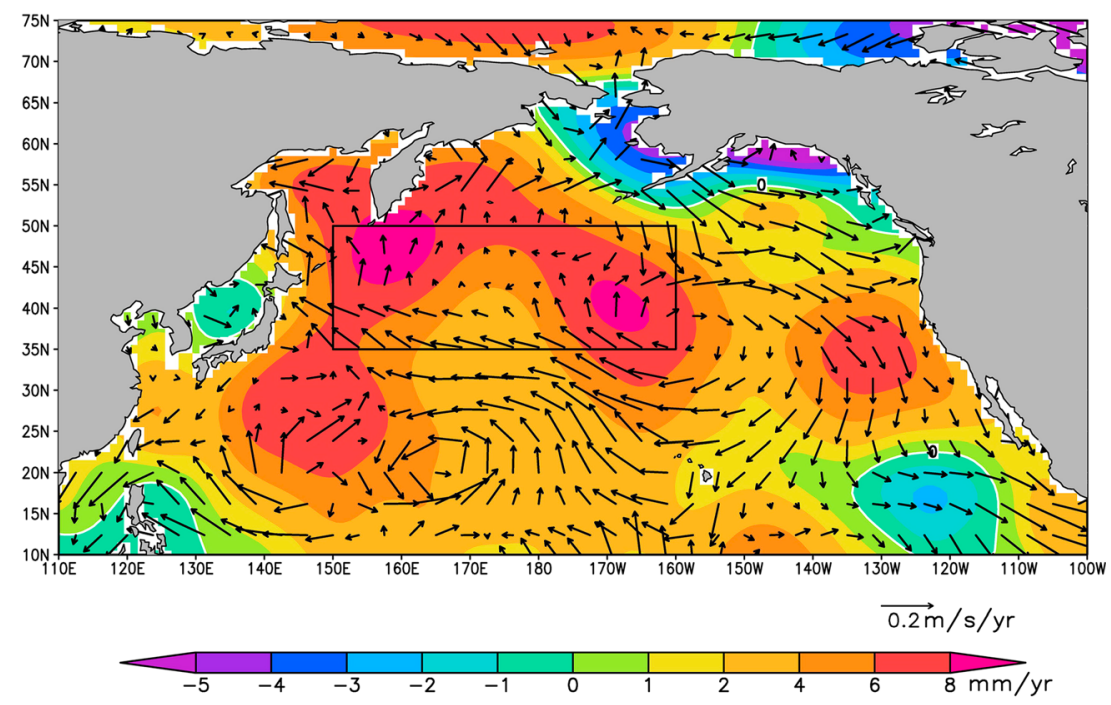

Figure 2. Linear trend of mass-induced sea surface height from GRACE observations for the period 2003-2011 (shaded), imposed on the linear trend of $10 \mathrm{~m}$ wind from NCEP/NCAR (vector). The white contours denote zero linear trend lines. 

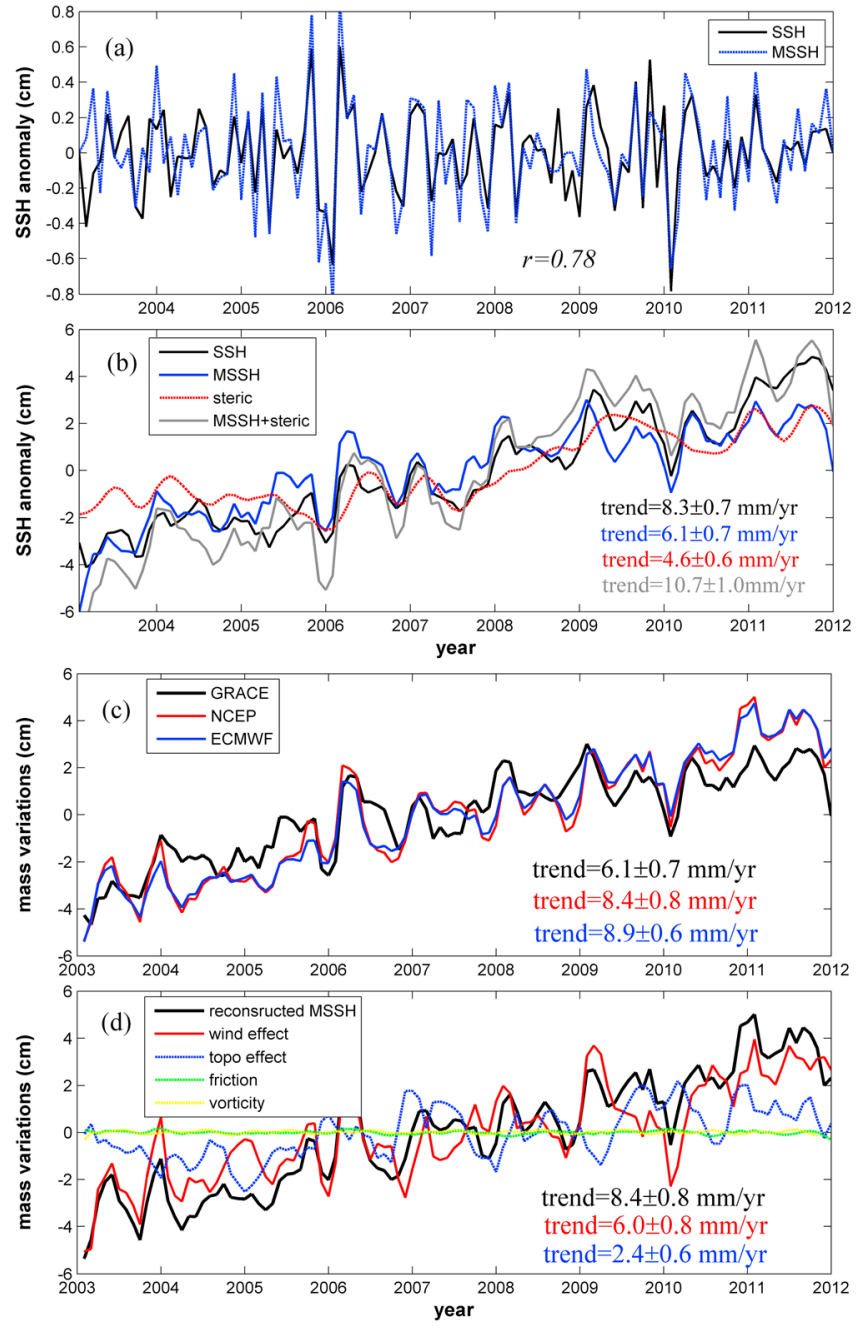

Figure 3. Time series of (a) high-frequency 1-3 months and (b) 3 month running mean of SSH (black), steric SSH (red), and MSSH (blue) anomalies, averaged over the black box in Figure $2\left(150^{\circ} \mathrm{E}-200^{\circ} \mathrm{E}, 35^{\circ} \mathrm{N}-50^{\circ} \mathrm{N}\right)$. Figure $3 \mathrm{a}$ is obtained from subtracting Figure $3 \mathrm{~b}$ from the original time series. (c) GRACE MSSH anomaly averaged over the black box in Figure 2 (black curve). Red and blue curves represent the reconstructed MSSH from equation (1) using all the RHS terms, corresponding to the use of NCEP/NCAR and ECWMF wind, respectively. (d) Contributions of wind and pressure forcing (solid red), effects of topography (dashed blue), bottom friction (dashed green), as well as sum of relative vorticity and vortex stretching to the full reconstructed MSSH using NCEP/NCAR wind.

(T/P and ERS-1/2, followed by Jason-1/2 and Envisat), distributed by Archiving, Validation, and Interpretation of Satellite Oceanographic data (AVISO, http://www.aviso. oceanobs.com/). In order to correct the aliasing of tides and barotropic variability, the altimeter data have been updated with the tidal model GOT2000 and the barotropic hydrodynamic model MOG2D-G [Volkov et al., 2007; Dibarboure et al., 2008]. The product is available on a $1 / 3^{\circ}$ Mercator grid at weekly intervals.

[8] A monthly $1^{\circ} \times 1^{\circ}$ gridded temperature and a salinity data set are used to estimate steric sea level change [Ishii and Kimoto, 2009]. These data cover the period from 1945 to 2011 , with depth from the surface to $700 \mathrm{~m}$. As for the GRACE data, only the 2003-2011 data are used.

[9] To estimate the barotropic oceanic response to wind forcing, we also used the National Centers for Environmental Prediction/National Center for Atmospheric Research (NCEP/ NCAR) reanalysis wind [Kalnay et al., 1996], European Centre for Medium-Range Weather Forecasts (ECMWF) (http://www.ecmwf.int/) winds, and ETOP05 bathymetric data [National Oceanic and Atmospheric Administration, 1988]. The ETOP05 data are smoothed and reconstructed on a $1^{\circ} \times 1^{\circ}$ grid.

\section{Results}

\subsection{Long-Term Variability of the Mass-Induced SSH}

[10] The large-scale MSSH variations are inferred from an empirical orthogonal function (EOF) analysis. The first two leading modes, as well as the corresponding principal components (PCs), are displayed in Figure 1. The first two modes account for $58 \%$ and $9 \%$ of the total variance. The first mode and its corresponding PC clearly reveal the long-term variability in the MSSH. The PC1 time series indicates a persistent rise of the global mean MSSH for the period 2003-2011 (Figure 1b). Remarkable positive trend appears in the northwestern North Pacific and high latitudes of the Southern Ocean. On the other hand, relatively large negative trends appear around southern Greenland, southern Alaska, and West Antarctica (Figure 1a); these negative trends are mostly due to leakage from the large ice melting in these regions instead of oceanic processes [Luthcke et al., 2006; Quinn and Ponte, 2010; Hill et al., 2011; Chambers and Bonin, 2012]. The PC2 time series peaks at about 4 year period, which denotes interannual variability (Figure 1d). Relatively strong variability in the MSSH appears in the northwestern North Pacific (Figure 1c).

[11] Figure 2 shows the local trends of observed MSSH and NCEP/NCAR surface wind. Most of the North Pacific shows MSSH rise for the period 2003-2011. The maximum rate of MSSH rise appears in the northwestern North Pacific. Three maximum centers ( $>6 \mathrm{~mm} / \mathrm{yr})$ are found east of Japan, south of Kamchatka Peninsula, and northwest of Hawaii Islands. It is worth noting that the atmospheric circulation during this period appeared in the form of anticyclonic circulation enhancement at midlatitudes to high latitudes in the North Pacific, which could be a potential forcing for the MSSH rise over the region.

\subsection{Contribution of Mass-Induced SSH to SSH}

[12] On an intraseasonal time scale (1-3 months), MSSH has a significant correlation with $\mathrm{SSH}(r=0.78$, significant at the 95\% level) in the northwestern North Pacific (Figure 3a), indicating that large-scale SSH variability for the periods of $1-3$ months is mainly controlled by barotropic variability, in agreement with previous results in Quinn and Ponte [2012]. They reported significant coherence between observed MSSH and SSH at high latitudes for periods of 14-180 days and midlatitudes for periods of 30-100 days. On interannual to decadal time scales, the contribution of MSSH to SSH cannot be ignored either (Figure 3b). There is a good agreement between the temporal evolution of MSSH and observed SSH anomalies $(r=0.90)$. A significant correlation still exists between them with the trends removed (Figure $3 b, r=0.54$, significant at 


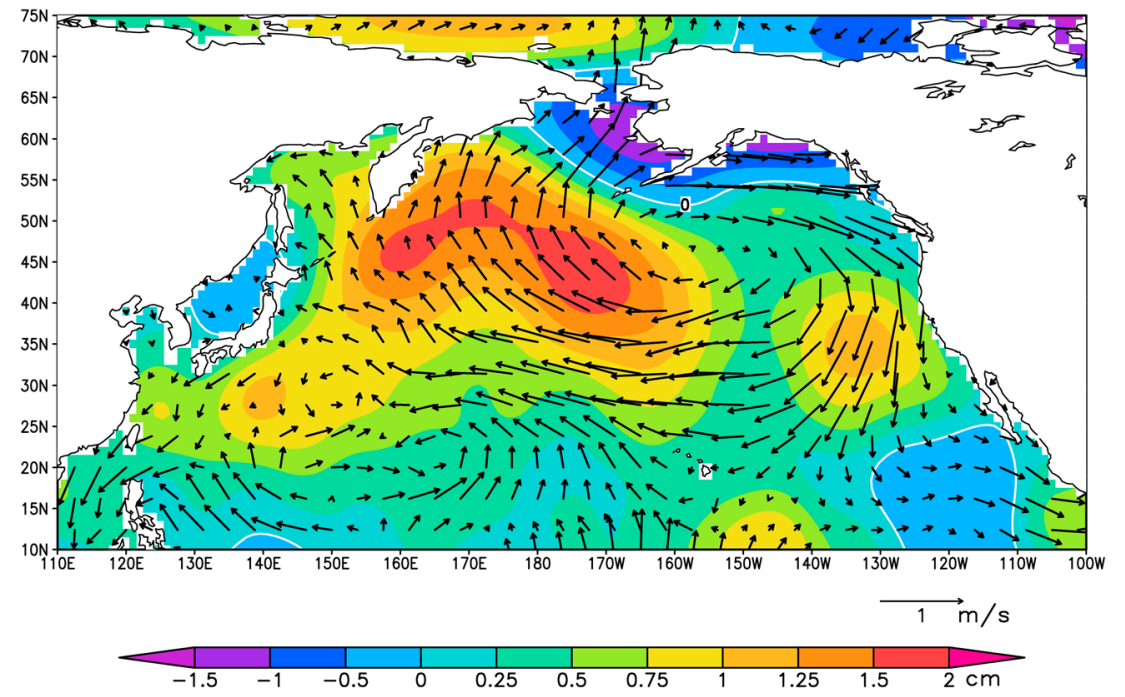

Figure 4. Regression coefficient of observed mass-induced sea surface height anomaly (color) and NCEP/NCAR $10 \mathrm{~m}$ wind (vector) on the normalized negative PDO index. The white contours denote zero regression coefficient lines.

the $95 \%$ level). For the period 2003-2011, SSH rose at a rate of $8.3 \pm 0.7 \mathrm{~mm} / \mathrm{yr}$. The MSSH had a positive trend of $6.1 \pm 0.7 \mathrm{~mm} / \mathrm{yr}$, about $74 \%$ of $\mathrm{SSH}$ rise rate. Chambers [2011] found that $\mathrm{MSSH}$, averaged over $160^{\circ} \mathrm{E}-185^{\circ} \mathrm{E}$, $35^{\circ} \mathrm{N}-45^{\circ} \mathrm{N}$, rose at a rate of $4.0 \pm 3.0 \mathrm{~mm} / \mathrm{yr}$ during $2003-$ 2010 (but $7.0 \pm 3.0 \mathrm{~mm} / \mathrm{yr}$ during 2003-2008), with a possible downturn in 2009-2010. In this study, MSSH, averaged over a larger region $\left(150^{\circ} \mathrm{E}-200^{\circ} \mathrm{E}, 35^{\circ} \mathrm{N}-50^{\circ} \mathrm{N}\right)$, shows a similar variability to that reported by Chambers [2011], but MSSH has a stronger variability, and the downturn did not last after 2009. A significant correlation is also found between steric SSH and SSH without or with their trends removed ( $r=0.89$ or 0.54 , significant at the $95 \%$ level). The steric SSH rise rate is $4.6 \pm 0.6 \mathrm{~mm} / \mathrm{yr}$ over $2003-2011$, about $55 \%$ of SSH rise rate. The correlation coefficient between $\mathrm{SSH}$ and the sum of its two components is 0.95 ( 0.54 with trends removed, significant at the $95 \%$ level), indicative of an excellent agreement between SSH and its two components.

[13] The sum of MSSH and steric SSH rose at a rate of $10.7 \pm 1.0 \mathrm{~mm} / \mathrm{yr}$ over 2003-2011, which is slightly larger than the trend of SSH. The discrepancy between SSH and the sum of its two components may be due to the uncertainties in the altimetry data, GRACE data, and Ishii data. Quinn and Ponte [2010] pointed out that uncertainty in ocean mass trends is up to $\sim 2.5 \mathrm{~mm} / \mathrm{yr}$ over $2003-2008$ from GRACE observations. In the region of study, the MSSH trend of $6.1 \pm 0.7 \mathrm{~mm} / \mathrm{yr}$ is more than twice of the uncertainty. Regional sea level change is associated with thermal, salinity, and mass redistribution, which is tied directly to the general circulation [Wunsch et al., 2007]. Since Ishii data contain temperature and salinity only in the upper $700 \mathrm{~m}$, the abyssal steric contribution caused by ocean circulation is not considered, which may bring uncertainty in steric SSH estimation. Despite of the noted discrepancy, the sea level budget in this region is closed within expected uncertainties.

\subsection{Origin of the Mass-Induced SSH Variability}

[14] Figure 2 suggests that the long-term change in surface wind may account for the increasing trend in MSSH in the northwestern North Pacific. To quantify the barotropic ocean response to atmospheric forcing, a barotropic vorticity equation is employed [Fu and Davidson, 1995; Vivier et al., 2005]. Following Boening et al. [2011], the MSSH is reconstructed as follows:

$$
\begin{aligned}
\eta^{x}= & \int_{\mathrm{xe}}^{x} \frac{1}{\beta}\left[\frac{f}{\rho g} \nabla \times \frac{\tau}{H}-\frac{f^{2}}{g^{2} H \rho} \frac{\partial P_{a}}{\partial t}-\frac{\partial}{\partial t} \nabla^{2} \eta\right. \\
& \left.+\frac{f^{2}}{g H} \frac{\partial \eta}{\partial t}+\frac{f}{H}\left(\frac{\partial \eta}{\partial x} \frac{\partial H}{\partial y}-\frac{\partial \eta}{\partial y} \frac{\partial H}{\partial x}\right)-\nabla \cdot\left(\frac{r}{H} \nabla \eta\right)\right]+\eta^{x e}
\end{aligned}
$$

where $\eta^{x}$ is the reconstructed MSSH, $\eta$ is the barotropic $\mathrm{SSH}$ (mass-induced SSH), $f=2 \Omega \sin (\phi), \Omega$ is the Earth's rotation rate, $\phi$ is the latitude, $\beta=\frac{\mathrm{d} f}{\mathrm{~d} y}, \rho$ is the seawater density, $g$ is the gravitational constant, $r$ is the damping/friction coefficient, $\tau$ is the wind stress, $H$ is the ocean depth, and $P_{a}$ is the sea level pressure. On the right-hand side (RHS), the first and second terms denote the forcing by wind stress curl and sea level pressure. The third term is the time rate of change of relative vorticity, the fourth term is the generation of vorticity due to the stretching of water column, and the fifth and sixth terms denote topographic and damping effects, respectively. $\eta^{x e}$ is the condition near the eastern boundary $\left(130^{\circ} \mathrm{W}\right)$. All data are smoothed over $5^{\circ} \times 5^{\circ}$ to suppress small-scale signals. There is a very good agreement between the observed MSSH and the reconstructed MSSH inferred from the NCEP/NCAR and ECMWF wind (Figure 3c). During 2003-2011, reconstructed MSSH forced by NCEP/ NCAR (ECWMF) wind rose at a rate of $8.4 \pm 0.8 \mathrm{~mm} / \mathrm{yr}$ $(8.9 \pm 0.6 \mathrm{~mm} / \mathrm{yr})$, which slightly overestimates the observed MSSH $(6.1 \pm 0.7 \mathrm{~mm} / \mathrm{yr})$. The correlation coefficient between the observed MSSH and the reconstructed MSSH based on NCEP/NCAR (ECMWF) wind is $0.88(0.89)$. After removing the trends, the correlation coefficient decreases to $0.51(0.53)$. The correlation is still significant at the $95 \%$ level, indicative of a good agreement between the reconstructed MSSH and the observed MSSH on subannual and interannual time scales.

[15] By comparing the observed/reconstructed MSSH with different terms on the RHS of equation (1) based on NCEP/ NCAR wind, the relative contribution of different processes can be assessed (Figure $3 \mathrm{~d}$ ). The contribution by the wind 
stress curl is the largest with a positive trend of $6.0 \pm 0.8 \mathrm{~mm} / \mathrm{yr}$, indicating the importance of atmospheric forcing. The topography term is the second largest, which has a positive trend of $2.4 \pm 0.6 \mathrm{~mm} / \mathrm{yr}$. The dashed green and yellow curves denote the friction and vorticity (sum of relative vorticity and vortex stretching) terms, respectively. They are close to zero; thus, their contributions to observed/reconstructed MSSH are negligible on an interannual time scale. The correlation coefficient between the wind stress curl term and the observed/ reconstructed $\mathrm{MSSH}$ is $0.88 / 0.89$. After removing the trends, the correlation coefficient decreases to $0.60 / 0.67$. The correlation is still significant at the $95 \%$ level, indicating the importance of atmospheric forcing on subannual and interannual time scales. The correlation between the topography term and the observed/reconstructed MSSH is not significant with the trends removed $(r=-0.24 / 0.019)$.

\section{Conclusions and Discussion}

[16] We have examined observed MSSH and its contribution to total SSH in the northwestern North Pacific for the period 2003-2011. The observed MSSH shows a strong positive trend and has a dominant contribution to the total $\mathrm{SSH}$ change. Analysis of the barotropic vorticity equation based on NCEP/NCAR reanalysis surface winds suggests that the observed MSSH trend is mainly induced by the enhancement of anticyclonic surface atmospheric circulation, which induces water mass convergence in the region.

[17] Since the GRACE data have a relatively short time span, the MSSH long-term trend patterns in Figure 2 are likely nonstationary in time, which may be related to the internal modes of climate variability, such as ENSO and PDO. Previous studies indicated that not all of the low-frequency variability in the MSSH is related to ENSO and that MSSH trend during 2003-2010 cannot be explained by ENSO either [Song and Zlotnicki, 2008; Chambers, 2011]. The PDO is a pattern of Pacific climate variability that shifts phase usually about every 20-30 years [Mantua et al., 1997]. Many studies suggested that the PDO may account for a significant part of interdecadal variability and decadal trend of SSH in the Pacific [e.g., Bromirski et al., 2011; Merrifield et al., 2012]. So far, the impact of PDO on MSSH variability in the North Pacific has been largely unexplored.

[18] Figure 4 shows the regression of observed MSSH and NCEP/NCAR $10 \mathrm{~m}$ wind upon a normalized negative PDO index. An anticyclonic atmospheric circulation is located at the midlatitudes to high latitudes in the North Pacific. Corresponding to the anticyclonic wind anomalies, positive MSSH anomalies are found in the North Pacific between $25^{\circ} \mathrm{N}$ and $55^{\circ} \mathrm{N}$. A high positive center is located in the northwestern North Pacific, with the central value of more than $2 \mathrm{~cm}$. The patterns of surface wind and MSSH associated with PDO are very similar to their local trends (Figure 2), indicating that the linear trends in MSSH and surface wind during 20032011 may be closely related to the negative trend in PDO.

[19] Acknowledgments. This work was supported by the National Basic Research Program of China (2010CB950303 and 2012CB955603) and the National Natural Science Foundation of China (41176023, 41276108, and 41006006). X.H.C. is also sponsored by "Youth Innovation Promotion Association," CAS (SQ201204, LTOZZ1202). Constructive remarks by two anonymous reviewers are greatly appreciated.

[20] The Editor thanks two anonymous reviewers for their assistance in evaluating this paper.

\section{References}

Bingham, R. J., and C. W. Hughes (2008), The relationship between seallevel and bottom pressure variability in an eddy permitting ocean model, Geophys. Res. Lett., 35, L03602, doi:10.1029/2007GL032662.

Boening, C., T. Lee, and V. Zlotnicki (2011), A record high ocean bottom pressure in the South Pacific observed by GRACE, Geophys. Res. Lett., 38, L04602, doi:10.1029/2010GL046013.

Boening, C., J. K. Willis, F. W. Landerer, R. S. Nerem, and J. Fasullo (2012), The 2011 La Niña: So strong, the oceans fell, Geophys. Res. Lett., 39, L19602, doi:10.1029/2012GL053055.

Bromirski, P. D., A. J. Miller, R. E. Flick, and G. Auad (2011), Dynamical suppression of sea level rise along the Pacific coast of North America: Indications for imminent acceleration, J. Geophys. Res., 116, C07005, doi:10.1029/2010JC006759.

Cazenave, A., and W. Llovel (2010), Contemporary sea level rise, Annu. Rev. Mar. Sci., 2(1), 145-173, doi:10.1007/s10236-010-0324-0.

Cazenave, A., R. S. Nerem (2004), Present-day sea level change: Observations and causes, Rev. Geophys., 42, RG3001, doi:10.1029/2003RG000139.

Cazenave, A., K. Dominh, S. Guinehut, E. Berthier, W. Llovel, G. Ramillien, M. Ablain, and G. Larnicol (2009), Sea level budget over 2003-2008: A reevaluation from GRACE space gravimetry, satellite altimetry and Argo, Global Planet. Change, 65(1-2), 83-88, doi:10.1016/j.gloplacha.2008.10.004.

Chambers, D. P. (2006a), Evaluation of new GRACE time-variable gravity data over the ocean, Geophys. Res. Lett., 33, LI7603, doi:10.1029/ 2006 GL027296.

Chambers, D. P. (2006b), Observing seasonal steric sea level variations with GRACE and altimetry, J. Geophys. Res., 111, C03010, doi:10.1029/ 2005JC002914.

Chambers, D. P. (2011), ENSO-correlated fluctuations in ocean bottom pressure and wind-stress curl in the North Pacific, Ocean Sci. Diss., 7, 685-692.

Chambers, D. P., and J. A. Bonin (2012), Evaluation of Release-05 GRACE time-variable gravity coefficients over the Ocean, Ocean Sci., 8, 589-868, doi:10.5194/os-8-859-2012.

Chambers, D. P., and J. K. Willis (2008), Analysis of large-scale ocean bottom pressure variability in the North Pacific, J. Geophys. Res., 113, C11003, doi:10.1029/2008JC004930.

Chen, J. L., C. R. Wilson, and B. D. Tapley (2013), Contribution of ice sheet and mountain glacier melt to recent sea level rise, Nat. Geosci., 6, 549-552, doi:10.1038/NGEO1829.

Church, J. A., and N. J. White (2006), A 20th century acceleration in global sealevel rise, Geophys. Res. Lett., 33, L01602, doi:10.1029/2005GL024826.

Dibarboure, G., O. Lauret, F. Mertz, V. Rosmorduc, and C. Maheu (2008), SSALTO/DUACS user handbook: (M)SLA and (M)ADT near-real time and delayed time products, CLS-DOS-NT-06.034, 39 pp., Aviso Altimetry, Ramonville St. Agne, France.

Douglas, B. C., M. S. Kearney, and S. P. Leatherman (Eds) (2001), Sea level Rise: History and Consequences, 232 pp., Academic, San Diego, Calif.

Fu, L.-L., and R. Davidson (1995), A note on the barotropic response of sea level to time dependent wind forcing, J. Geophys. Res., 100, 24,955-24,963, doi:10.1029/95JC02259.

Gill, A. E., and P. P. Niiler (1973), The theory of the seasonal variability in the ocean, Deep Sea Res. Oceanogr. Abstr., 20, 141-177.

Hill, E. M., J. L. Davis, M. E. Tamisiea, R. M. Ponte, and N. T. Vinogradova (2011), Using a spatially realistic load model to assess impacts of Alaskan glacier ice loss on sea level, J. Geophys. Res., 116, B10407, doi:10.1029/ 2011JB008339.

Ishii, M., and M. Kimoto (2009), Reevaluation of historical ocean heat content variations with time-varying XBT and MBT depth bias corrections, J. Oceanogr., 65, 287-299, doi:10.1007/s10872-009-0027-7.

Kalnay, E., et al. (1996), The NCEP/NCAR 40-year reanalysis project, Bull. Am. Meteorol. Soc., 77, 437-471.

Leuliette, E. W., and J. K. Willis (2011), Balancing the sea level budget, Oceanography, 24(2), 122-129, doi:10.5670/oceanog.2011.32.

Levitus, S., J. Antonov, T. Boyer (2005), Warming of the world ocean, 1955-2003, Geophys. Res. Lett., 32, L02604, doi:10.1029/2004GL021592.

Llovel, W., M. Becker, A. Cazenave, S. Jevrejeva, R. Alkama, B. Decharme, H. Douville, M. Ablain, and B. Beckley (2011), Terrestrial waters and sea level variations on interannual time scale, Global Planet. Change, 75(1-2), 76-82, doi:10.1016/j.gloplacha.2010.10.008.

Luthcke, S. B., H. J. Zwally, W. Abdalati, D. D. Rowlands, R. D. Ray, R. S. Nerem, F. G. Lemoine, J. J. McCarthy, and D. S. Chinn (2006), Recent Greenland ice mass loss by drainage system from satellite gravity observations, Science, 314, 1286-1289.

Mantua, N. J., S. R. Hare, Y. Zhang, J. M. Wallace, and R. C. Francis (1997), A Pacific interdecadal climate oscillation with impact on salmon production, Bull. Am. Meteorol. Soc., 78(6), 1069-1079, doi:10.1175/1520-0477(1997) $078<1069$ :APICOW $>2.0 . \mathrm{CO} ; 2$.

Merrifield, M. A., P. R. Thompson, and M. Lander (2012), Multidecadal sea level anomalies and trends in the western tropical Pacific, Geophys. Res. Lett., 39, L13602, doi:10.1029/2012GL052032. 
National Oceanic and Atmospheric Administration (1988), Digital Relief of the Surface of the Earth, Data Announce. 88-MGG-02, Natl. Geophys. Data Cent., Boulder, Colo.

Quinn, K. J., and R. M. Ponte (2010), Uncertainty in ocean mass trends from GRACE, Geophys. J. Int., 181, 762-768, doi:10.1111/j.1365246X.2010.04508.x.

Quinn, K. J., and R. M. Ponte (2012), High frequency barotropic ocean variability observed by GRACE and satellite altimetry, Geophys. Res. Lett., 39, L07603, doi:10.1029/2012GL051301.

Song, Y. T., and V. Zlotnicki (2008), Subpolar ocean-bottom-pressure oscillation and its links to the tropical ENSO, Int. J. Remote Sens., 29, 6091-6107, doi:10.1080/01431160802175538.

Tapley, D. B., S. Bettadpur, J. C. Ries, P. F. Thompson, and M. M. Watkins (2004), GRACE measurements of mass variability in the Earth system, Science, 305, 503-505.
Vivier, F., K. A. Kelly, and M. Harismendey (2005), Causes of large-scale sea level variations in the Southern Ocean: Analyses of sea level and a barotropic model, J. Geophys. Res., 110, C09014, doi:10.1029/ 2004JC002773.

Volkov, D. L., G. Larnicol, and J. Dorandeu (2007), Improving the quality of satellite altimetry data over continental shelves, J. Geophys. Res., 112, C06020, doi:10.1029/2006JC003765.

Willebrand, J., S. G. H. Philander, and R. C. Pacanowski (1980), The oceanic response to large-scale atmospheric disturbances, J. Phys. Oceanogr., 10, 411-429.

Willis, J. K., D. P. Chambers, and R. S. Nerem (2008), Assessing the globally averaged sea level budget on seasonal to interannual timescales, J. Geophys. Res., 113, C06015, doi:10.1029/2007JC004517.

Wunsch, C., R. Ponte, and P. Heimbach (2007), Decadal trends in sea level pattern: 1993-2004, J. Clim., 20, 5889-5911. 